\title{
Effects of Leaf Wetness Duration and Temperature on Infection Efficiency, Latent Period, and Rate of Pustule Appearance of Rust in Alfalfa
}

\author{
D. H. Webb and F. W. Nutter, Jr.
}

Department of Plant Pathology, Iowa State University, Ames 50011.

Accepted for publication 27 May 1997.

\begin{abstract}
Webb, D. H., and Nutter, F. W., Jr. 1997. Effects of leaf wetness duration and temperature on infection efficiency, latent period, and rate of pustule appearance of rust in alfalfa. Phytopathology 87:946-950.

Dew and growth chamber tests were conducted on the alfalfa cultivar Ranger to determine the effect of duration of leaf wetness and temperature on several components of the alfalfa rust (Uromyces striatus) monocycle. Duration of leaf wetness and temperature both had significant effects on pustule development. Infection efficiency (number of alfalfa rust pustules per leaf) increased linearly as duration of leaf wetness was increased from 4 to $24 \mathrm{~h}$ after inoculation. There was an inverse linear relationship between temperature and infection efficiency as indicated by the slope $(-5.73)$ of the regression line relating the number of pustules

Inoculated alfalfa plants exposed to constant temperatures of $15,18,21$, 24,27 , or $30^{\circ} \mathrm{C}$ after an initial 24-h leaf wetness period $\left(19^{\circ} \mathrm{C}\right)$ did not significantly affect infection efficiency $(P \leq 0.05)$, but did affect the time from inoculation to the time when $50 \%$ of the pustules $\left(\mathrm{T}_{50}\right)$ were visible (i.e., latent period). Using this state variable definition, latent period was found to decrease with increasing temperature. When latent period was measured as a rate variable, the rate of pustule appearance (as affected by temperature) was best described by the Gompertz model. Thus, temperature and length of the initial leaf wetness period had a greater impact on infection efficiency than did postinfection (post-leaf wetness) temperatures, whereas increasing temperatures from 15 to $30^{\circ} \mathrm{C}$ had a significant effect on shortening the latent period $\left(\mathrm{T}_{50}\right)$ and increasing the rate of pustule appearance.
\end{abstract} per leaf to increasing temperatures between 17.5 and $28^{\circ} \mathrm{C}$. Infection efficiency was approximately 20 times greater at $17.5^{\circ} \mathrm{C}$ than at $28^{\circ} \mathrm{C}$.
Additional keywords: disease components, resistance screening.
Alfalfa rust, caused by Uromyces striatus J. Schröt, causes significant losses to alfalfa, Medicago sativa L. (lucerne), in many parts of the world $(4,5,7,14,17)$. The disease occurs mid-to-late in the growing season in Iowa (14), and alfalfa rust can cause severe losses when forage harvests are delayed $(1,4,5,7)$. Additional losses may also occur when alfalfa plants are predisposed to winter kill after being weakened by alfalfa rust epidemics that occur prior to frost $(1,10)$.

Sowing alfalfa cultivars with acceptable levels of rust resistance is the strategy most often deployed to increase stand persistence (7, 20 ), and screening for rust resistance continues to be a priority in most alfalfa breeding programs $(4,7,9,16,20)$. The current standard tests (10) used to characterize rust resistance in alfalfa cultivars recommends a constant temperature of $25^{\circ} \mathrm{C}$ for all phases of the alfalfa rust monocycle, which is the time from inoculation to the time that rust pustules appear; thus, alfalfa genotypes may then be evaluated for resistance to rust. Despite this recommended protocol, a range of temperature and leaf wetness durations have been used in other studies to facilitate the development of this disease. For example, McMurtrey et al. (9) incubated plants at $22^{\circ} \mathrm{C}$ for a 48-h leaf wetness period under darkness following inoculation, whereas Al-Hamdany (1) utilized a 16-h leaf wetness period at $20^{\circ} \mathrm{C}$ to facilitate infection and pustule development. While these methods have proven useful in differentiating the resistance and susceptibility of alfalfa cultivars to rust (based on the size and numbers of pustules), the varying methodologies utilized by researchers identifies a need to more precisely define the quanti-

Corresponding author: F. W. Nutter, Jr.; E-mail address: fwn@iastate.edu

Publication no. P-1997-0624-02R

(C) 1997 The American Phytopathological Society tative effects of temperature and leaf wetness duration on individual disease components (e.g., infection efficiency, pustule size, latent period, and sporulation capacity) of the alfalfa rust monocycle $(2,12,13,15,20)$. According to Vanderplank's equivalence theorem (19), quantitative information concerning the effect of environment on specific disease components should also be useful in estimating the quantitative impacts of plant genotypes with partial resistance (i.e., components of resistance) on the rate of disease progress in the field $(2,12,13,20)$. Applying this theorem at the disease components level, a 50\% reduction in infection efficiency, whether it is due to a less favorable environment, partial resistance, or a less aggressive pathogen isolate, would all have equivalent epidemiological effects on the rate of disease progress in the field (19). Moreover, quantitative information concerning the effects of leaf wetness duration and temperature on specific components of alfalfa rust development may be valuable in predicting the impact of global climate change on alfalfa rust epidemics in different geographical regions. Therefore, the objectives of this study were to (i) quantify the effects of leaf wetness duration and temperature on infection efficiency and (ii) quantify the effects of postinfection temperature (i.e., the effect of temperature following an initial 24-h period of leaf wetness) on infection efficiency, time to $50 \%$ pustule appearance (latent period), and rate of pustule appearance.

\section{MATERIALS AND METHODS}

Host and pathogen materials. Urediniospores of $U$. striatus were obtained in 1992 from diseased alfalfa (cultivar Pioneer 5262) from a field established in Ankeny, IA, in 1991. Urediniospores of the pathogen were increased on the cultivar Ranger (susceptible to rust) and collected weekly using a cyclone spore collector (Instrument Shop, Iowa State University, Ames) and vacuum pump (Vacu-Aide model 721; DeVilbiss Co., Somerset, PA). 
To minimize variation in urediniospore viability among experiments, urediniospores were stored in the dark at $3^{\circ} \mathrm{C}$ for 2 weeks, or less, prior to inoculation. 'Ranger' alfalfa plants were grown from seed in $10-\mathrm{cm}^{3}$ Cone-tainers (Stuewe \& Sons, Inc., Corvallis, OR) in the greenhouse under a 16-h photoperiod at approximately $22^{\circ} \mathrm{C}$. To obtain plants of uniform regrowth and age, plants were clipped regularly at the full flowering stage to a height approximately $4 \mathrm{~cm}$ above the top of each Cone-tainer.

Inoculation procedure. Following 3 weeks of regrowth, alfalfa plants 20 to $30 \mathrm{~cm}$ high were inoculated in a spore inoculation tower. The inoculation tower consisted of a metal cylinder (119 $\mathrm{cm}$ in diameter and $128 \mathrm{~cm}$ tall) equipped with a turntable at the bottom that rotated at a rate of five revolutions per minute. An atomizer was positioned through the side of the chamber at a height of $35 \mathrm{~cm}$ above the top of the plants (20).

Spore suspensions were produced by mixing urediniospores with a petroleum-based oil (Isopar M; Exxon Company, U.S.A., Houston), determining the number of spores per milliliter with a hemacytometer, and then diluting to obtain the desired concentrations (20). Plants were inoculated by placing one replication of experimental units on the turntable and injecting $10 \mathrm{ml}$ of urediniospore suspension (spores per milliliter are given for each experiment) into the tower at the rate of $1.3 \mathrm{ml} / \mathrm{min}$ at $138 \mathrm{kPa}$ to attain a desired density of 22 to 50 urediniospores $/ \mathrm{cm}^{2}$ of leaf area (20). Following inoculation, plants were removed from the cylinder, misted with deionized distilled water, and placed in a dew chamber (Percival Manufacturing Co., Boone, IA) under darkness.

Infection efficiency experiments. Plants were inoculated with 35 urediniospores $/ \mathrm{cm}^{2}$ of leaf area and placed in a dew chamber in the dark at $20^{\circ} \mathrm{C}$. Plants were removed from the dew chamber 4 , $8,12,16,24$, or $32 \mathrm{~h}$ after inoculation and then placed in a growth chamber at $20^{\circ} \mathrm{C}$ with a 16 -h photoperiod and light intensity of 150 to $170 \mu \mathrm{E} \mathrm{m}^{-2} \mathrm{~s}^{-1}$ for an additional 13 days. At this time, infection efficiency was determined by counting the number of pustules on the adaxial surfaces of the top three fully expanded leaves that were present on the day of inoculation. There were four replications per leaf wetness period treatment and two plants (six leaves) per replication arranged in a randomized complete block design within a single dew chamber. The experiment was conducted twice.

The effect of temperature during the initial 24-h period of leaf wetness (in darkness) on infection efficiency was determined by inoculating two plants with 50 urediniospores $/ \mathrm{cm}^{2}$ of leaf area. Experimental units were randomly assigned to one of five dew chambers (relative humidity $[\mathrm{RH}]=100 \%$ ) set at either $17.5,19,22$, 25 , or $28^{\circ} \mathrm{C}$ for 24 -h leaf wetness periods. There were five replications per temperature treatment, with replications within dew chambers arranged in a randomized complete block design with two plants per replication. Following removal from dew chambers, plants were then placed on a greenhouse bench in a randomized complete block design at approximately $22^{\circ} \mathrm{C}$ with a 16 -h photoperiod for an additional 13 days. Infection efficiency (number of pustules per leaf) was determined by counting the number of pustules on the adaxial surface of the top three fully expanded leaves located immediately below the whorl at the time of inoculation. The experiment was conducted twice with randomization of temperatures assigned to specific dew chambers.

Latent period experiments. Plants were inoculated with 22 urediniospores $/ \mathrm{cm}^{2}$ of leaf area and placed in a dark dew chamber for $24 \mathrm{~h}$ at $19^{\circ} \mathrm{C}$. Following the leaf wetness period $(100 \% \mathrm{RH})$, plants were placed randomly in growth chambers $(\mathrm{RH}=70 \pm 5 \%)$ at constant temperatures of $15,18,21,24,27$, or $30^{\circ} \mathrm{C}$ and a $16-\mathrm{h}$ photoperiod. Latent period, defined as the time from inoculation to the time when $50 \%$ of the pustules were visible $\left(\mathrm{T}_{50}\right.$, a state variable), was determined by counting the number of sporulating pustules each day on the top three leaves, beginning when pustules were first visible and continuing until there was no further increase in pustule numbers for two consecutive days. For this experiment, the leaf area of each three-leaf sample was measured using a DIAS II leaf area meter (Decagon Devices, Inc., Pullman, WA) and the number of pustules per square centimeter of leaf area was calculated and used as a measure of infection efficiency. The linear, logistic, exponential, Gompertz, and probit transformations were applied to the data, and the most appropriate transformation to quantify the rate of pustule appearance over time (i.e., latent period measured as a rate variable) was determined using the computer program EPIMODEL (11). Latent period measured as a state variable $\left(\mathrm{T}_{50}\right)$ was then determined by solving for the time (days) when $50 \%$ of the pustules had appeared, using the most appropriate linearized model $(2,11,13)$. Thus, the effect of temperature on latent period was characterized by measuring a state variable $\left(\mathrm{T}_{50}\right)$ and a rate variable (rate of pustule appearance). A randomized complete block design was used, and there were four replications per treatment and three plants per replication. The experiment was performed twice.

Data analysis. Simple linear regression analyses were used to characterize stimulus-response relationships between leaf wetness duration and temperature (stimuli) with treatment means $(3,6)$ for infection efficiency, latent period, and rate of pustule appearance (response variables). The SAS PROC GLM procedure (SAS Institute, Cary, NC) was used for all regression analyses. The parameters used to evaluate regression models were the $F$ statistic for the overall model indicating a linear relationship between $\mathrm{x}$ and $y(P \leq 0.05)$, the coefficient of determination $\left(r^{2}\right)$, the standard error of the estimate for $\mathrm{y}\left(\mathrm{SE}_{\mathrm{y}}\right)$, and a subjective evaluation of the residuals plotted against the independent variable $(3,6,11)$. Each experiment was performed twice, and a $t$ test was used to compare regression parameters obtained from the initial and repeated experiments $(3,6)$. Data from repeated experiments were combined with initial experiments if regression parameters were not significantly different $(P \leq 0.05)$ using a $t$ test $(3,6)$.

\section{RESULTS}

Infection efficiency. Infection efficiency increased as leaf wetness duration increased from $4 \mathrm{~h}$ (60.0 pustules/leaf) to $24 \mathrm{~h}$ (183.4 pustules/leaf), and then declined to 121.3 pustules/leaf at $32 \mathrm{~h}$ of wetness (Fig. 1). Linear regression (6) was used to quantify the

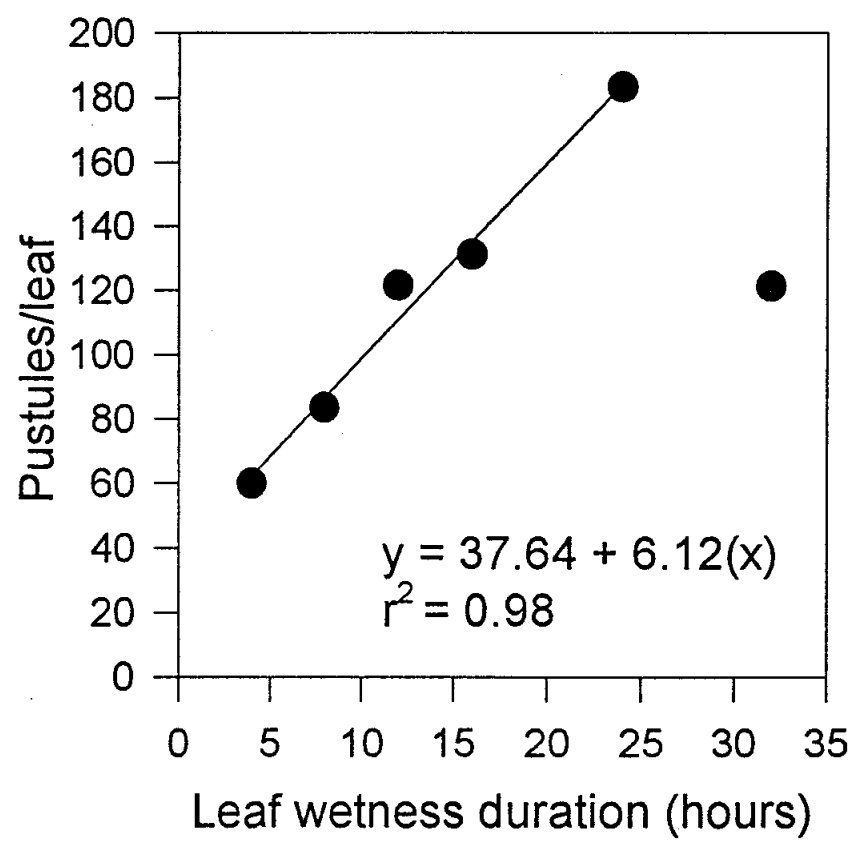

Fig. 1. Linear regression of duration of leaf wetness (hours) and infection efficiency (pustules per leaf) for Uromyces striatus on the alfalfa cultivar Ranger. 
relationship between duration of leaf wetness (hours) and infection efficiency for the linear portion of this curve (i.e., between 4 and $24 \mathrm{~h}$ following inoculation), and leaf wetness duration explained $98.0 \%$ of the variation in infection efficiency $\left(r^{2}=0.98\right)$ within this range. Infection efficiency increased by 6.1 pustules/ leaf for each $1 \mathrm{~h}$ of increase in leaf wetness duration $(P \leq 0.0009$, $\mathrm{SE}_{\mathrm{y}}=6.93$ ).

As temperature increased from 17.5 to $28^{\circ} \mathrm{C}$, infection efficiency decreased in a linear fashion, and temperature during the initial 24-h leaf wetness period explained $97.3 \%$ of the variation in the change in infection efficiency $\left(P \leq 0.0012, \mathrm{SE}_{\mathrm{y}}=4.07\right)$. For each one degree increase in temperature, infection efficiency decreased by 5.73 pustules/leaf (Fig. 2).

Infection efficiency was not significantly affected by temperature after the initial 24-h period of leaf wetness (Table 1). Although $21^{\circ} \mathrm{C}$ resulted in the highest infection efficiency among the post-leaf wetness temperatures tested, infection efficiencies among the different postinfection temperatures were not significantly different from one another using analysis of variance and the WallerDuncan $k$-ratio test $(P \leq 0.05)$. The $F$ statistic for the regression model and the $t$ statistic for the slope relating postinoculation (wetness) temperature to infection efficiency were also not significant $(P \leq 0.05)$.

Latent period. Pustule appearance (as affected by temperature after the initial 24-h wetness period) was plotted with respect to

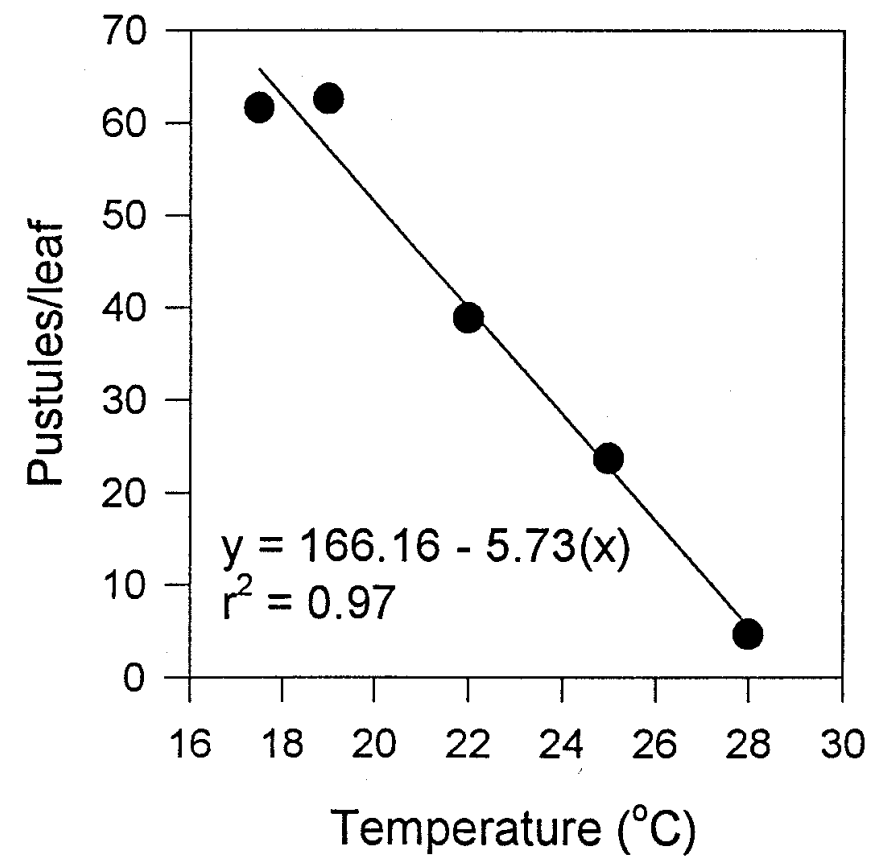

Fig. 2. Effect of temperature during the 24-h period of leaf wetness following inoculation on infection efficiency (pustules per leaf) of Uromyces striatus on the alfalfa cultivar Ranger.

TABLE 1. Effect of temperature after an initial 24-h period of leaf wetness on infection efficiency (pustules/ $/ \mathrm{cm}^{2}$ )

\begin{tabular}{lcc}
\hline & \multicolumn{2}{c}{ Pustules $/ \mathrm{cm}^{2}$} \\
\cline { 2 - 3 } Temperature $\left({ }^{\circ} \mathrm{C}\right)$ & First experiment & Second experiment \\
\hline 15 & $4.59 \mathrm{a}^{\mathrm{z}}$ & $3.49 \mathrm{a}$ \\
18 & $4.15 \mathrm{a}$ & $4.06 \mathrm{a}$ \\
21 & $5.33 \mathrm{a}$ & $5.37 \mathrm{a}$ \\
24 & $5.09 \mathrm{a}$ & $3.97 \mathrm{a}$ \\
27 & $4.33 \mathrm{a}$ & $4.94 \mathrm{a}$ \\
30 & $4.10 \mathrm{a}$ & $4.98 \mathrm{a}$ \\
\hline
\end{tabular}

${ }^{\mathrm{z}}$ Means followed by the same letter are not significantly different according to the Waller Duncan $k$-ratio test, $k=100\left(P \leq \_0.05\right)$. days after inoculation, resulting in curves that were asymmetrical (Fig. 3A). When the cumulative number of pustules per square centimeter of leaf tissue was regressed on days after inoculation for each post-leaf wetness temperature (Fig. 3B), the rate of pustule appearance (i.e., latent period measured as a rate variable) with respect to days after inoculation was best described by the Gompertz transformation. The selection of this model was based on significant $F$ statistics, higher $r^{2}$ values, lower $\mathrm{SE}_{\mathrm{y}}$ values, and the lack of patterns in residual plots compared with other model transformations evaluated (monomolecular, exponential, logistic, probit, and linear) (data not shown). To quantify the effect of temperature on the rate of pustule appearance using the Gompertz model, cumulative number of pustules per square centimeter was divided by the final number of pustules per square centimeter, transformed to gompits, and gompits were regressed against time (Fig. 3B, Table 2). As temperature increased from 15 to $30^{\circ} \mathrm{C}$, the estimated Gompertz parameter describing the rate of pustule appearance (gompits per day) increased linearly with respect to days after inoculation, and temperature explained $95 \%$ of the variation in the
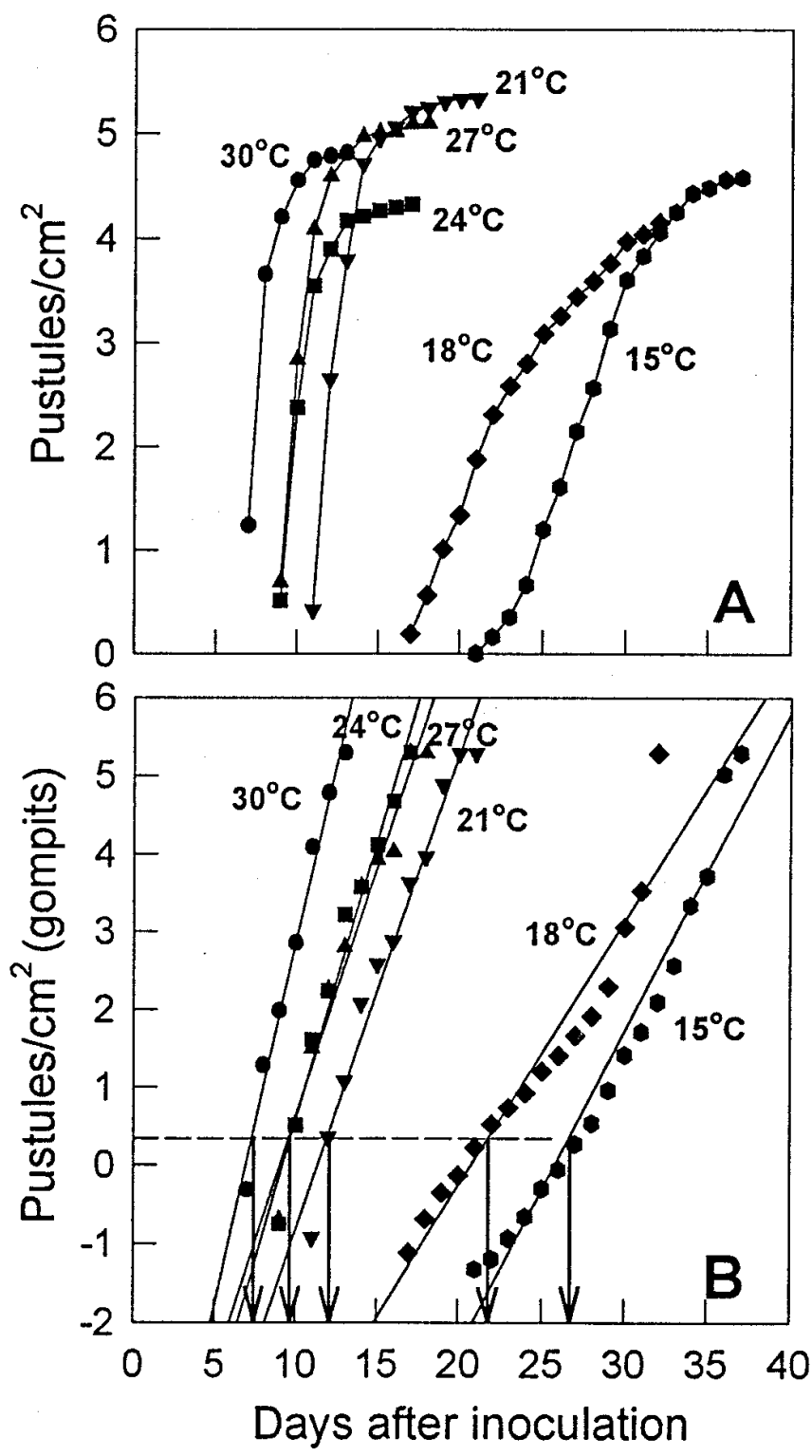

Fig. 3. A, Effect of temperature on the cumulative appearance of Uromyces striatus pustules on the alfalfa cultivar Ranger with respect to days after inoculation. B, Effect of temperature on the rate of pustule appearance (gompits per day) of Uromyces striatus using the Gompertz model and on time to $50 \%$ pustule appearance $(\downarrow)$. 
rate of pustule appearance (Fig. 4). For each one degree increase in temperature, the estimated Gompertz rate parameter increased by 0.034 gompits/day $\left(P \leq 0.0006, \mathrm{SE}_{\mathrm{y}}=0.044\right)$.

The time to first pustule appearance decreased as postinfection temperatures increased (Table 2). Pustules were visible as early as 7 days after inoculation at $30^{\circ} \mathrm{C}$, but not until day 21 at $15^{\circ} \mathrm{C}$. Pustules emerged over a 10-day period at $30^{\circ} \mathrm{C}$ as compared with a period of 16 days at $15^{\circ} \mathrm{C}$ (Table 2). An increase in temperature from 15 to $30^{\circ} \mathrm{C}$ decreased the time to $50 \%$ pustule appearance $\left(\mathrm{T}_{50}\right)$ from 26.8 to 7.5 days. This relationship was found to be linear if latent periods $\left(\mathrm{T}_{50}\right.$ values) were first transformed to natural logarithms and then regressed with respect to temperature ( $P \leq$ $\left.0.0016, \mathrm{SE}_{\mathrm{y}}=0.137\right)$; and for each one degree increase in temperature, $\ln \left(\mathrm{T}_{50}\right)$ decreased by 0.082 (Fig. 5), with temperature explaining $91.8 \%\left(r^{2}\right)$ of the variation in $\ln \left(\mathrm{T}_{50}\right)$.

\section{DISCUSSION}

Monocyclic experiments are often performed to predict the effects of host genotype or climatic factors (temperature, relative humidity, leaf wetness duration, etc.) on the rate of polycyclic disease development in the field $(2,13,15,20)$. Although standard tests to characterize alfalfa cultivars for resistance to alfalfa rust recommend using a constant temperature of $25^{\circ} \mathrm{C}$ for monocyclic experiments $(8,10)$, we found that monocyclic processes such as infection efficiency, latent period, and sporulation capacity responded

TABLE 2. Effect of postinfection temperature on the rate of pustule appearance, days to first and final pustule appearance

\begin{tabular}{lccc}
\hline $\begin{array}{l}\text { Temperature } \\
\left({ }^{\circ} \mathrm{C}\right)\end{array}$ & $r_{\mathrm{g}}{ }^{\mathrm{z}}$ & $\begin{array}{c}\text { Time to first pustule } \\
\text { (days after inoculation) }\end{array}$ & $\begin{array}{c}\text { Time to last pustule } \\
\text { (days after inoculation) }\end{array}$ \\
\hline 15 & 0.429 & 21 & 36 \\
18 & 0.476 & 17 & 32 \\
21 & 0.671 & 11 & 21 \\
24 & 0.771 & 9 & 18 \\
27 & 0.791 & 9 & 17 \\
30 & 0.947 & 7 & 17 \\
\hline
\end{tabular}

${ }^{\mathrm{z}}$ Estimated Gompertz rate parameter describing the rate of pustule appearance as a function of days after inoculation.

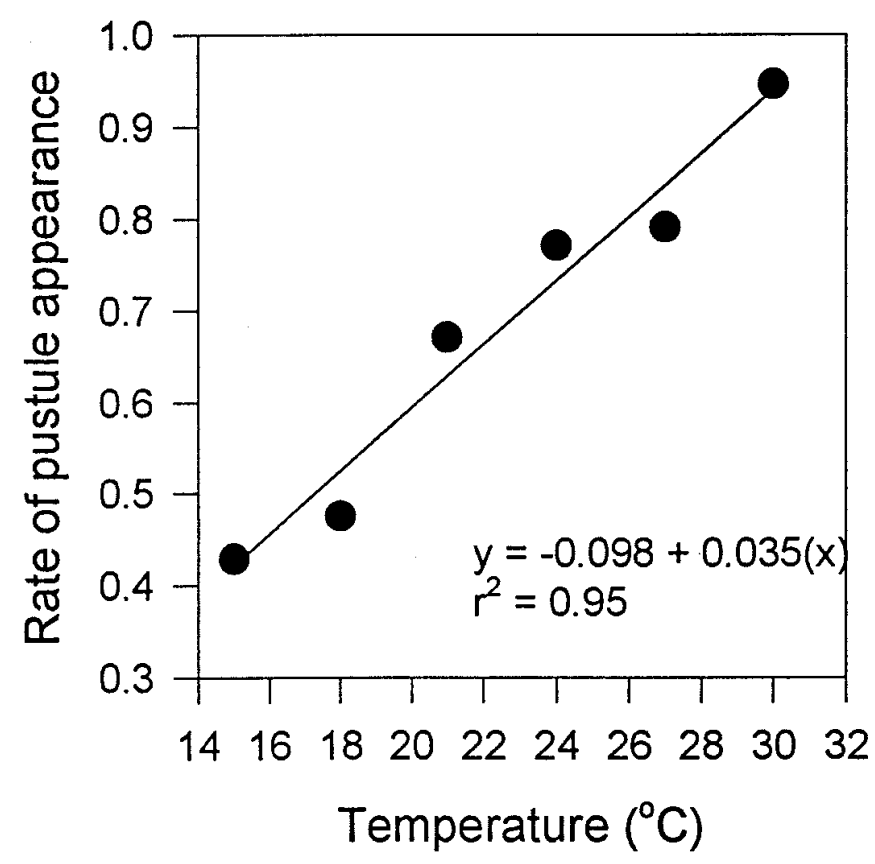

Fig. 4. Linear regression quantifying the relationship between the rate of pustule appearance (gompits per day) and temperature. differentially to specific temperature and moisture conditions. Based on our results, the use of a single constant temperature for all components of the alfalfa rust monocycle would limit both pustule number and rate of emergence. For example, we found that, for 'Ranger', $17.5^{\circ} \mathrm{C}$ was the optimum temperature for infection efficiency during the first $24 \mathrm{~h}$ of leaf wetness following inoculation. Although infection efficiency was highest at $17.5^{\circ} \mathrm{C}$, it may be more practical to use $19^{\circ} \mathrm{C}$ to measure infection efficiency, because we sometimes observed necrotic spotting of leaves at $17.5^{\circ} \mathrm{C}$. This spotting, which resembles symptoms caused by potassium deficiency, interfered with the expansion of pustules, as well as our counting of them. This spotting also prevented us from accurately measuring infection efficiency at temperatures below $17.5^{\circ} \mathrm{C}$. We found that reducing the temperature from the recommended 25 to $19^{\circ} \mathrm{C}$ during the initial 24-h leaf wetness period following inoculation increased infection efficiency by approximately $300 \%$. The standard tests used to characterize alfalfa cultivars for rust resistance recommend atomizing alfalfa plants with a suspension of approximately $3.5 \times$ $10^{5} \mathrm{spores} / \mathrm{ml}$ until runoff $(8)$. Inoculation protocols using a leaf wetness temperature of $19^{\circ} \mathrm{C}$ to optimize infection efficiency should conserve the amount of inoculum required to perform cultivar evaluations and may reduce potential problems as far as spores clumping or competing for infection sites and resources.

The higher infection efficiencies at 17.5 and $19^{\circ} \mathrm{C}$ may have biological importance with regard to the occurrence and rate of alfalfa rust development in the field. Rizvi and Nutter (14) reported that alfalfa rust was first observed in Iowa anytime from midAugust until frost. Mean daily temperatures for the mid-August through mid-October range from 12.9 to $23.6^{\circ} \mathrm{C}$ (18). Daily minimum temperatures during this time are mostly below $20^{\circ} \mathrm{C}$, and it is during the nighttime hours when the most favorable temperatures $\left(<20^{\circ} \mathrm{C}\right)$ and extended dew periods for infection are most likely to coincide. Thompson (17) has also reported that alfalfa rust is more severe during the cooler months in South Africa. In contrast, Inch et al. (5) found rust to be more severe in the warmer months in Queensland, Australia, which may indicate the existence of ecotypes that may require different temperature optima for cultivar evaluations.

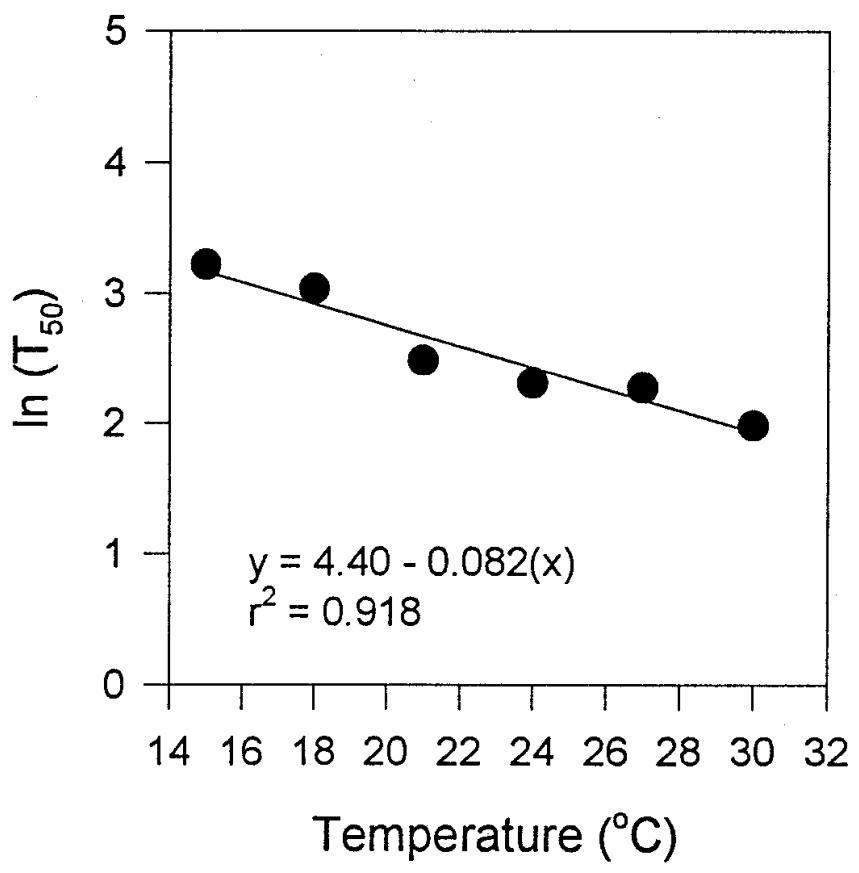

Fig. 5. Effect of temperature on ln latent period (time when $50 \%$ of the pustules are visible, $\mathrm{T}_{50}$ ) of Uromyces striatus on the alfalfa cultivar Ranger. 
Our results agree with the standard tests (10) in recommending an initial 24-h leaf wetness period following inoculation to optimize infection efficiency. The length of the leaf wetness period used in other published reports has ranged from 16 to $48 \mathrm{~h}(1,7-9,16)$.

The effect of the postinfection temperature on infection efficiency following the initial 24-h leaf wetness period may be host dependent. Al-Hamdany (1) found that a postinfection (leaf wetness) temperature of $25^{\circ} \mathrm{C}$ provided the highest number of pustules per leaf for the cultivar Kanza. We found, however, that the temperature during the postinfection period did not significantly influence infection efficiency, indicating that the most critical effects of both temperature and duration of leaf wetness on infection efficiency of alfalfa rust occurs during the initial (24-h) leaf wetness period immediately following urediniospore deposition.

Shaner (15) used probit analysis to calculate the time from inoculation to the time when $50 \%$ of rust pustules on wheat were sporulating. Probit analysis is commonly used in dose-response studies in which the dose (stimulus) is a chemical concentration (not time) and the response is the inhibition or death of a target biological population. Since time to a developmental stage, rather than the dosage needed to kill or inhibit a biological population, is used to quantify latent period, we hypothesized that one of the population growth models (exponential, logistic, monomolecular, or Gompertz), as opposed to the probit transformation, might provide a better statistical model to describe the relationship between time $(t)$ and latent period (time to 50\% pustule appearance). Compared with all other models tested (including the probit transformation), the Gompertz model, based on regression parameters and statistics such as the $F$ statistic for each model, $r^{2}$ values, the standard errors of the y-estimate, and inspection of residual plots, was found to best describe the asymmetrical, sigmoid-shaped increase in pustule appearance with respect to time. The biological explanation for the asymmetrical increase in cumulative pustule appearance over time is unknown at this time, but it is possible that earlier occurring infections are having a delaying effect on the rate of pustule appearance of later infections. Additional experiments are needed to test this hypothesis.

\section{ACKNOWLEDGMENTS}

Research was supported by State and Hatch funds allocated to the Iowa Agricultural and Home Economics Experiment Station and, in part, by the Leopold Center for Sustainable Agriculture. Journal paper J-16444 of the Iowa Agriculture and Home Economics Experiment Station, Ames, IA 50011. Project no. 3394

\section{LITERATURE CITED}

1. Al-Hamdany, M. A. 1980. Overwintering of Uromyces striatus Schroet. and some effects of temperature, photoperiod, moisture, and leaf age on alfalfa rust development. Ph.D. dissertation. Kansas State University, Manhattan (Dissertation Abstr. 80-24236).

2. Aquino, V. M., Shokes, F. M., Gorbet, D. W., and Nutter, F. W., Jr. 1995. Late leaf spot progression on peanut as affected by components of partial resistance. Plant Dis. 79:74-78.

3. Gomez, K. A., and Gomez, A. A. 1984. Statistical Procedures for Agricultural Research. John Wiley \& Sons, New York.

4. Hill, R. R., Jr., Sherwood, R. T., and Dudley, J. W. 1963. Effect of recurrent phenotypic selection on resistance of alfalfa to two physiological races of Uromyces striatus medicaginis. Phytopathology 53:432-435.

5. Inch, J. J., Irwin, I. A. G., and Gray, R. A. 1993. Seasonal variation in lucerne foliar diseases and cultivar reaction to leaf spot pathogens in the field in southern Queensland. Aust. J. Exp. Agric. 33:343-348.

6. Kleinbaum, D. G., and Kupper, L. L. 1978. Applied regression analysis and other multivariate methods. Duxbury Press, North Scituate, MA.

7. Koepper, J. M. 1942. Relative resistance of alfalfa species and varieties to rust caused by Uromyces striatus. Phytopathology 32:1048-1057.

8. McMurtrey, J. E., Aycock, M. K., Jr., and Elgin, J. M., Jr. 1979. Examination of the inheritance of rust (Uromyces striatus Schroet.) resistance in five alfalfa populations. Page 69 in: Agronomy Abstracts. American Society of Agronomy, Madison, WI.

9. McMurtrey, J. E., III, and Elgin, J. H., Jr. 1984. Rust resistance. Standard tests to characterize pest resistance in alfalfa cultivars. U.S. Dep. Agric. Misc. Pub. 1434:26-27.

10. North American Alfalfa Improvement Conference. 1991. Standard Tests to Characterize Alfalfa Cultivars. 3rd ed. U.S. Dep. Agric./Agric. Res. Serv., Beltsville, MD.

11. Nutter, F. W., Jr., and Parker, S. K. 1996. Fitting disease progress curves using EPIMODEL. Pages 24-28 in: Exercises in Plant Disease Epidemiology. L. Francl and D. H. Neher, eds. The American Phytopathological Society, St. Paul, MN.

12. Pedersen, E. A., and Morrall, R. A. A. 1994. Effects of cultivar, leaf wetness duration, temperature, and growth stage on infection and development of Ascochyta blight of lentil. Phytopathology 84:1024-1030.

13. Ricker, M. D., Beute, M. K., and Campbell, C. L. 1985. Components of resistance in peanut to Cercospora arachidicola. Plant Dis. 69:1059-1064.

14. Rizvi, S. S. A., and Nutter, F. W., Jr. 1993. Seasonal dynamics of alfalfa foliar pathogens in Iowa. Plant Dis. 77:1126-1135.

15. Shaner, G. 1980. Probits for analyzing latent period data in studies of slow rusting resistance. Phytopathology 70:1179-1182.

16. Skinner, D. Z., and Stuteville, D. L. 1989. Influence of temperature on expression of resistance to rust in diploid alfalfa. Crop Sci. 29:675-677.

17. Thompson, A. H. 1985. A Preliminary Survey of Fungal Diseases of Lucerne in the Republic of South Africa. Republic of South Africa, Department of Agriculture and Water Supply Technical Communication 197, Johannesburg, South Aftrica.

18. U.S. Department of Commerce. 1893-1990. Climatological data. National Oceanic and Atmospheric Administration, Washington, DC.

19. Vanderplank, J. E. 1963. Plant Disease Epidemics and Control. Academic Press, New York.

20. Webb, D. H., Nutter, F. W., Jr., and Buxton, D. R. 1996. Effect of acid detergent lignin concentration in alfalfa leaves on three components of resistance to alfalfa rust. Plant Dis. 80:1184-1188. 